\title{
Revisiting the Role of Traditional, Electronic and Mobile-Based Communication Channels in the Pharmaceutical Industry of Lithuania
}

\author{
${ }^{1,2}$ ISM University of Management and Economics \\ Arkliu st. 18, LT-01305, Vilnius, Lithuania \\ E-mail.vilaur@ism.lt, jovita.butkeviciene@gmail.com \\ ${ }^{3}$ Lancaster University Management School \\ Lancaster, LA1 4YX, United Kingdom, \\ E-mail.l.salciuviene@lancaster.ac.uk
}

Vilte Auruskeviciene ${ }^{1}$, Jovita Butkeviciene ${ }^{2}$, Laura Salciuviene ${ }^{3}$

cross $^{r e f}$ http://dx.doi.org/10.5755/j01.ee.26.5.12510

\begin{abstract}
The study investigates communication channels currently used to disseminate medical information and examines perceptions of general practitioners (GPs) about perceived value, perceived reliability and channel usage frequency of traditional and alternative (i.e., electronic and mobile-based) channels. A total of 254 GPs in Lithuania were surveyed. The findings suggest that pharmaceutical companies still rely on sales representatives to disseminate the newest information about prescription drugs to GPs. The results suggest that leading experts (i.e., opinion leaders) in the healthcare industry add significantly to increasing GPS' intentions to prescribe specific drugs to their patients. Conferences organised by local and international scientific societies are considered to be the most reliable communication channels. Local websites designed for GPs have the highest perceived value among GPs. Further, statistically significant differences among different GPS' age groups were confirmed regarding channel preference and their perceived reliability: international scientific conferences and international health journals were more popular and perceived as more reliable among younger GPs compared to more senior GPs.
\end{abstract}

Keywords: Communication Channels, Pharmaceutical Industry, Perceptions Of General Practitioners, Lithuania.

\section{Introduction}

Pharmaceutical companies have faced positive and negative changes in the industry over the last few years. For instance, a report by Price Waterhouse Coopers (2007) states that demographic, epidemiological and economic factors contribute to the changes in the pharmaceutical market: the world's population increases (it is expected that the population will increase up to 7,6. billion by 2020), the age of the population increases (by 2020, about 719,4 million of people, or $9,4 \%$ of the world's population will be 65 years of age and older compared to the 7,3\% of the population of the same age in 2005). Traditionally, older people consume more drugs than younger. According to the Health Department in the United Kingdom, four out of five people over the age of 75 years consume at least one prescribed drug and $36 \%$ of those people use four or more prescribed drugs (UK Department of Health, 2001). Although the above changes contribute to the development of the pharmaceutical industry positively, other factors, such as drug patent expiry time, decreasing portfolio of new products, tighter promotion policy regulations of generic drugs (Businessvibes, 2012), increasing influence of health authorities on requesting more informed decisions affects drug selection by GPs, shorter lists of new prescription drugs, stricter laws banning or limiting pharmaceutical sales representatives' access to healthcare practitioners impede the development of the pharmaceutical industry.
Evidence suggests that pharmaceutical companies invest one-third of all sales revenues on drug promotion (World Health Organization, 2015). In most cases, those promotion expenses are much higher than R\&D new drug development expenses (Anderson, 2014). Furthermore, complex legal requirements in European countries and fierce competition in the pharmaceutical market of prescription drugs raises expectations not only to comply with those regulations but also search for the most effective promotion channels to disseminate information about newest drugs available on the market. Factors such as the application of national laws, product life cycle, patent expiry date, national level of economy and regional disparities within a country might affect companies' decisions about the most suitable communication channels to reach their target groups.

Healthcare professionals (or General Practitioners) are the major targets of pharmaceutical companies (Schulz et al., 2014; Scott et al., 2013) because of two reasons: (a) physicians are the key decision-makers in selecting specific drugs for their patients' prescriptions (Gonul et al., 2001); (b) companies are banned by law from advertising their prescription drugs directly-to-consumers (with the exception of US and New Zealand). The most common communication channel to access GPs and inform them about new drugs from pharmaceutical companies would be through sales representatives (personal selling).

The literature devotes considerable attention to the concept of communication channels, specifically, personal selling, which has been popular in promoting new and 
existing drugs in the market in the pharmaceutical industry. With constant advancements in the technological environment, more innovative versions of traditional communication channels become available to the industry thus diminishing the significance and popularity of personal selling. In addition, other reasons are considered by some sources emphasising a decreasing effectiveness of pharmaceutical sales representatives in drug promotion (PWC, 2009). Increasing numbers of pharmaceutical sales representatives, decreasing average representative age and productivity have contributed to this negative trend (Lendskold, 2005). Decreasing productivity of pharmaceutical sales representatives has also been affected by a limited amount of time they are permitted to spend with a GP during their visit. An average visit lasts less than two minutes and only $43 \%$ of visits can be considered "face2face" (Mack, 2005).

Although electronic and mobile-based communication channels are becoming increasingly popular among companies, there is little research that would consider a holistic approach to prescription drug promotion, which would combine personal selling with alternative communication channels and would investigate GPs' perceptions of this approach. Therefore, this research aims to revisit the traditional in-person sales model most commonly used by pharmaceutical companies to date and establish GPs' perceptions of traditional and alternative electronic \& mobile-based channels in the context of an Eastern European country. Our findings contribute to the initial insights into GPs' perceptions of both traditional and alternative (electronic and mobile-based) communication channels in the pharmaceutical industry of Lithuania and advise pharmaceutical companies to combine relevant communication channels in the most effective ways to reach their target groups in the prescription drug market.

\section{Theoretical Background}

\section{Traditional Communication Channel in the Pharmaceutical Industry: Personal Selling}

Literature discusses various communication channels used in the pharmaceutical industry for drug promotion (e.g., pharmaceutical sales representative visits, conferences organized by pharmaceutical companies, websites dedicated to healthcare professionals, medical information sent to GPs by e-mail or SMS).

There is an ongoing debate in the literature regarding the role and prominence of personal selling in drug promotion. One group of researchers consider in-person selling to be important (e.g., Pedan \& Wu, 2011), with positive effects on product promotion (Cavusgil \& Calantone, 2011). Most GPs agree that personal meetings with pharmaceutical representatives are informative (Chimonas et al., 2007) and serve as a necessary source of information (Jones et al., 2001).

Typically, representatives are considered to be knowledgeable in presenting the newest information about complex drugs and predicting future trends in the pharmaceutical industry; they tend to understand needs of GPs and their patients very well (Hutt \& Speh, 2007). When meeting GPs, pharmaceutical sales representatives would discuss several types of drugs, provide additional scientific information about new drugs, link a GP's experience with medical products available on the market and supply materials about diagnostic and treatment options. It is not unusual for sales representative to invite GPs to attend scientific events organised by pharmaceutical companies or local scientific societies.

Although visits by pharmaceutical sales representatives have been considered one of the most influential communication channels (Scott et al., 2013), it remains unclear what perceptions GPs hold about other communication channels used to disseminate medical information in terms of their reliability, usage frequency and value perceptions of those channels. This is especially so in light of emerging electronic and mobile-based communications, which have challenged the significance of in-person representation in the pharmaceutical industry (Rod \& Sounders, 2009).

\section{Alternative Communication Channels in the Pharmaceutical Industry}

Due to an increasing usage of alternative communication channels to access medical information, a traditional doctor-representative conversation might not be longer considered the most effective and the only one channel available on the market for information exchange (Ketis \& Kersnik, 2013; Rod \& Sounders, 2009). For instance, websites have become irreplaceable for information search by GPs (Kim \& King, 2009; Kim, 2011; Purcell et al., 2002), they facilitate much quicker and more convenient access to medical information and are perceived as reliable sources of information (Mack, 2005) that positively affect product choices (Castronovo \& Huang, 2012).

In recent years, electronic and mobile-based communication channels have become popular tools for contacting customers. Channels, such as E-detailing and websites have been used increasingly by pharmaceutical companies (Qanadilo \& Chol, 2011). The researchers suggest that perceived value among GPs of information received by e-mails is increasing, for instance, communication of medical information by e-email received the highest evaluation among one-way communication channels (Reast et al., 2001).

\section{Internet-Based Communication Channels}

The Internet is considered as a relatively new promotion tool in the pharmaceutical industry. This communication channel has become a very popular source to seek for medical information. Majority of pharmaceutical companies have their own websites where they provide health and drug-related information, advertise events organised by companies, but some of those companies choose to target only health specialists and limit access to their websites to those target customers (David, 2001).

Pharmaceutical companies have started investing in the development of websites, portals and e-detailing (Qanadilo \& Choi, 2012) to disseminate the newest medical information to GPs. However, information on websites has one major drawback, such as information security online: 
information dedicated to GPs cannot be accessed by their patients in countries where laws prohibit advertising prescription drugs directly to consumers. Also, discussion forums raise information security issues concerning the information provided by fellow patients about drugs in experience sharing activities online.

\section{Academic Journals as Communication Channels}

Findings from previous research on the influence of alternative channels, such as academic journals and their effects on GPs' prescription intentions, are contradictory (Reast et al., 2011; Vancelik et al., 2009). Although some studies report this channel being perceived as a reliable and informative source of information among GPs (Stross et al., 2009), others suggest that more often information by email is preferred to academic journals (Reast et al., 2011).

Based on those varying findings reported in previous studies we conclude that a variety of reasons might have affected inconsistencies of preferences among GPs: limited time available for information search, analysis and interpretation; limited availability of free academic sources as majority of articles have to be purchased or an annual membership is required and access is granted to members only; existing language barrier preventing GPs from reading the most recent scientific publications in foreign languages.

\section{Scientific Conferences As Communication Channels}

A communication channel, namely, scientific communities and conferences organised by pharmaceutical companies also receives some attention in the literature on its importance in disseminating information to GPs and its influence on GPs' drug prescribing intentions, but with conflicting results. For instance, (Burashnikova et al., 2008) suggest that practicing medical doctors are not very interested in attending conferences. Their finding supports (Prosser et al., 2003) study indicating that only a small percent of respondents are interested in conferences as a communication channel. Other research points out more positive outcomes of this channel (e.g., Pitt \& Neil, 1998), such as high perceived value, high reliability and level of detail that conferences can offer (Mack, 2005). Reast et al., 2011) investigated the importance of four communication channels where conferences \& events organised by pharmaceutical companies received highest scores on value perceptions in an international context. McGettigan, Golden et al., 2001) evaluated the impact of events on different product life cycle stages. Their findings suggest that nearly half of the respondents agreed with positive effects on increasing GPs' intentions to select new drugs; about one fifth of GPs considered this channel to be significant in increasing their intentions to select drugs from a mature product life cycle stage.

\section{Opinion leaders as communication channels}

In the pharmaceutical industry, opinion leaders are also used as an effective communication channel for drug promotion. They would have an extensive experience in clinical research, publish articles in international and national journals (Flicker, 2012), they would be well respected by their busy colleagues willing to listen to them about the benefits of the latest drugs on the market (Janakiraman et al., 2008). Companies start promoting their new drugs to opinion leaders a year before the drug is introduced into the market (Stros et al., 2009) and use opinion leaders to promote the drug in the introductory product life cycle stage (Groves et al., 2002) as well as in the maturity product life cycle stages (Nair et al., 2010).

Positive feedback from innovators and early adopters about new drugs in the market could also play an important role in drug promotion, but the frequency of introducing innovations into the market needs to be considered. Although the pharmaceutical industry is well known for introducing new products into the market frequently, there are not many innovators-volunteers willing to try innovative drugs. Innovators are well aware of possible benefits of new drugs, but they also have to be willing to take risks associated with possible negative side effects. Early adopters are among the first ones to adopt new products and some of them might become opinion leaders who are able to influence others (Perreault \& McCarthy, 2002).

\section{Research Questions}

Based on the above literature review on both traditional and alternative communication channels, this study raises the following research questions: GPs?

RQ1: How does the newest medical information reach

RQ2: How do GPs perceive both traditional and alternative communication channels used to disseminate medical information?

This study aims to provide answers to these questions.

\section{Research Design}

\section{Choice of the Country}

There are specific laws regulating promotional activities of sales representatives in different countries. For instance, in some European countries (e.g., Slovakia, Hungary) pharmaceutical sales representatives' visits are strictly prohibited. In Lithuania, by law, duration of sales representatives' visits to GPs is limited: the law prohibits representatives' visits during GPs' surgery hours, while meetings outside working hours are permitted. As there is no law prohibiting pharmaceutical companies to disseminate medical information through sales representatives in Lithuania, this country is deemed to be a suitable research context to achieve the aim of our study.

\section{Pharmaceutical Industry}

The pharmaceutical industry is rather complex and controversial in today's world. According to (Levy, 1994), it is R\&D and Information Service market. On one hand, the main aim of the industry is to increase the quality of people's life and supply pharmaceutics that many people require in both developed and developing parts of the world. On the other hand, the industry aims to earn profits and therefore has to address some ethical issues in their drug promotion. 
This industry contains several rather unique characteristics that differentiate it from other industries. Those are discussed below in greater depth.

The pharmaceutical industry is one of the most intensively $\mathrm{R} \& \mathrm{D}$ oriented industries where an innovation process is the key competitive advantage. $\mathrm{R} \& \mathrm{D}$ investment in this industry is among the highest in comparison to other R\&D oriented industries (Levy, 1994). New drug development is characterised as very uncertain and extremely risky: only one in 60000 synthesised molecules can be evaluated as "very successful" (Jaakkola \& Renko, 2007), only one in 5000-10 000 molecules can be approved for further drug development and only three in five new products would become profitable (Folland, Goodman \& Stano, 2004). Thus, finding new communication channels to promote drugs is crucial to ensure higher returns on investment.

The pharmaceutical industry is one of the most regulated and controlled industries (Folland et al., 2004). According to Castagnoli (2008), ,the pharmaceutical industry's character - its products, messages, promo channels and even its audiences - have been determined by governmental regulation and trade conventions“ (p. 82).

Many governmental and public authorities (e.g., Food and Drug Administration in the USA, European Medicines Agency in Europe, National Drug Control Agency under The Health Ministry of Lithuania) regulate activities of the pharmaceutical industry and communcation channels they use to promote drugs to consumers. In Lithuania, „The Pharmaceutical Marketing Code" was introduced following an agreement among representatives of the Association of Ethical Pharmaceutical Companies, the Association of Drug Manufacturers and the Association of the Pharmaceutical Industry. The aim of this document is to guarantee responsible, ethical and professional drug promotion to health care professionals. The document contains not only principles of ethical marketing but also consequences of ignoring the law of ethical drug promotion.

Most ethical pharmaceutical companies adhere to strict internal regulations for drug promotion. Those rules are often more stringent than the „Marketing Code“. Internal regulations govern the company's activities, such as compliance with legal and regulatory requirements of the Republic of Lithuania and Code of Ethics in the pharmaceutical industry. They also define the following: the company will not perform surreptitious promotion; promotional messages will be clear, accurate, coordinated, honest, objective, comprehensive and based on scientifically valid assessments of data.

\section{Control Mechanisms in the Pharmaceutical Industry}

One of the pharmaceutical industry control mechanisms refers to a patent system as every new drug is registered under a separate patent that expires in 20 years (Harms et al., 2002). Usually, patent is issued after the new molecule has been registered, but the process of converting a molecule into a drug, which can be introduced into the market takes about ten (Jaakkola \& Renko, 2007) or even twelve years (Harms et al., 2002). Therefore, pharmaceutical companies aim to cover their $R \& D$ costs within 7-10 years (Jaakkola \& Renko, 2007; Cavusgil \& Calantone, 2011).

After the patent expiry date, generic alternatives (International Non-proprietary Names [INN]) (i.e., substitutes of the same molecule) become available on the market (WHO, 2012). Usually, substitutes are possible only for the same therapeutic group (Folland et al., 2004). Several important reasons need to be considered for generic medicines to increase their market share.

Some reasons refer to expiring patents for many original drugs or a policy of the public authorities. By issuing regulations supporting penetration of generic drugs, public authorities aim to reduce the prescription drug budget. Therefore, those regulations (or in some caseslaws) significantly worsen selling conditions for original drugs. Not every manufacturer of original drugs can meet new requirements issued by public authorities and might decide to withdraw from the market or target direct-toconsumer (pharmaceutics sold over-the counter) drug market only.

\section{Budget Decisions in New Drug Promotion}

Marketing communication is an essential part connecting the results of research, innovation and consumers. The effectiveness of different communication channels used to promote new and mature drugs differs (McGettigan et al., 2001), but the industry benefits from a variety of communication channels available to companies to reach their target audiences (DeLaat et al., 2002).

In the early stages of the patented product life cycle only competing products (different molecules) of the same therapeutic group can be considered as substitutes. Promotional budget allocation depends on the product life cycle. According to (DeLaat et al., 2002), the peak of the promotional investment is recorded in the second year of the product life cycle, while about half of that amount is granted for the following 4-7 years. Later, investment for promotion is consistently falling and after 15 years no more than $20 \%$ of the initial budget is invested into promoting the product. Interestingly, after the patent expiry date (when generics enter the market) investments in promoting the original drugs still remain high.

Previously presented investment distribution by years suggests that promotion is used not only to gain but also to sustain market share by maximising the protection from generic substitutes.

\section{Prescription Drug Market}

The study focuses on prescription drug market, which is rather different from other drug markets. Prescription drug market can be characterised by high competition, strict laws regulating advertising and personal selling approaches, inelastic pricing and information asymmetry (Castagnoli, 2008; Cavusgil \& Calantone, 2011; DeLaat et al., 2002; Levy, 1994; Pantelic, 2009; Rod \& Saunders, 2009). Also, the final decision about the prescription drugs is always made by GPs because they write prescriptions to their patients. In contrast to many other markets, in the prescription drug market patients do not make the final decision about which prescription drug they should use (David, 2001; Folland et al., 2004; Jaakkola \& Renko, 
2007; Kim \& King, 2009; Kumar \& Shafali, 2010; Ladeira et al., 2011).

Contrary to other countries, where direct-to-consumer advertising of prescription drugs can be combined with industry-to-healthcare (directly to GPs) advertising (e.g., in USA and New Zealand), combined promotion activities for prescription drugs are prohibited by law in Lithuania. In this country, only healthcare professionals (in our research - GPs) can receive information about prescription drugs available on the market. They are expected to pass that information on to their patients and to inform them about benefits and drawbacks of those drugs. Furthermore, as 97 $\%$ of prescription drugs are covered by the Health Ministry of Lithuania (Lithuanian PharmaZoom Data, 2012), Lithuanian prescription drug market was selected to investigate GPs perceptions of communication channels used to communicate information about both new and existing prescription drugs available on the market in this study.

\section{Sample}

The total population for this study consists of 4691 registered GPs in Lithuania (Lithuanian Department of Statistics, 2012). In total, 290 GPs were approached in surgeries or at various events organised for health practitioners and personally invited to take part in the survey. A total of 254 usable responses were obtained following the questionnaire screening process, which found three invalid questionnaires (89\% response rate). The data were collected in big cities and small towns of Lithuania: Vilnius (38 responses), Klaipeda (33 responses), Kaunas (77 responses), Siauliai (32 responses), Panevezys (12 responses), other towns (62 responses). The average age of respondents was $51,5( \pm 9,74)$ years.

\section{Measures}

The survey instrument was designed according to (Churchill \& Iacobucci, 2005) recommendations. The instrument comprises three parts: (a) introduction, (b) main body of the questionnaire, and (c) demographics. Questions for the main part were derived from the literature. A 7-point Likert scale was used to gauge respondent perceptions (1=least important; 7=most important). A list of 17 communication channels that are used by pharmaceutical companies (e.g., pharmaceutical sales representatives, conferences organized by pharmaceutical companies, websites dedicated to healthcare professionals, medical information sent by email or SMS) was prepared. Those channels were selected from the literature and other information sources dedicated to healthcare practitioners. The survey instrument was pretested with seven respondents who were asked to fill in the questionnaire before administering the main study.

\section{Data Collection Method}

After a careful assessment of elements suggested by (Aaker et al., 2012) to be considered before making the final decision about the most suitable data collection method to answer research questions raised in this study, such as sampling, type of population, form and content of questions, an expected response rate and the costs involved in collecting data for the study, a survey was deemed the most suitable data collection method for this research.

Survey data collection method has several advantages: (a) distribution and collection of questionnaires can be managed by assistants of a principal investigator; (b) any questions raised by respondents about the empirical study can be answered instantly by a person distributing a questionnaire; (c) longer questionnaires can be used (a number of questions in a questionnaire does not reduce respondent numbers); (d) a direct contact with assistant ensures high response rates: 70-80\%. The major drawback of this data collection method refers to high costs required to hire assistants to distribute and collect questionnaires (Aaker et al., 2012).

\section{Data analysis technique}

Data was analysed using SPSS 14 . Means $(\bar{\chi})$, standard deviations (SD) and Mann-Whitney $U$ test was utilised to calculate the findings.

\section{Results and Discussion}

Results of the study suggest that the most commonly used communication channels in Lithuania are pharmaceutical sales representatives and conferences organised by pharmaceutical companies to reach GPs with medical information. Besides those two channels, the results suggest alternative channels that GPs consider as being reliable, having high perceived value and contributing significantly to their drug-prescribing intentions. The main findings of the study are discussed below to provide an answer to each research question.

\section{How does the newest medical information reach GPs?}

To address the first research question (RQ1: how does the newest medical information reach GPs?), channel usage frequency and channel reliability are discussed. Significant links between channel usage frequency, reliability and channels' contribution to increasing GPs' drug-prescribing intentions are identified.

Evidence suggests that pharmaceutical representatives $(\bar{\chi}=6,0 \pm 1,262)$, conferences organised by pharmaceutical companies in Lithuania $(\bar{\chi}=5,48 \pm 1,466)$ and conference presentations by pharmaceutical representatives in healthcare institutions $(\bar{\chi}=5,30 \pm 1,580)$ are most often used to provide the newest medical information to GPs in Lithuania. This finding corresponds to earlier results reported in the literature (Handa et al., 2013; Prosser et al., 2003; Jones et al., 2001) suggesting that pharmaceutical representatives remain a popular means to interact with their target audience, while alternative (i.e., electronic and mobile-based) communication channels, such as sending information by e-mail $(\bar{\chi}=2,70 \pm 1,826)$ or SMS $(\bar{\chi}=1,69 \pm 1,322)$, are used less frequently (Table 1$)$. 
Channel usage frequency

\begin{tabular}{|l|c|c|}
\hline \multicolumn{1}{|c|}{ Channel } & Mean & SD \\
\hline Pharmaceutical representatives & 6,00 & 1,262 \\
\hline $\begin{array}{l}\text { Conferences organised by } \\
\text { pharmaceutical companies in } \\
\text { Lithuania }\end{array}$ & 5,48 & 1,466 \\
\hline $\begin{array}{l}\text { Conference presentations by } \\
\text { pharmaceutical representatives in } \\
\text { healthcare institutions }\end{array}$ & 5,30 & 1,580 \\
\hline E-mail & 2,70 & 1,826 \\
\hline $\begin{array}{l}\text { Phone calls from pharmaceutical } \\
\text { representatives }\end{array}$ & 2,15 & 1,607 \\
\hline Sending information by SMS & 1,69 & 1,322 \\
\hline
\end{tabular}

Conferences organised by local $(\bar{\chi}=5,78 \pm 1,290)$ and international $(\bar{\chi}=5,67 \pm 1,311)$ scientific societies as well as leading experts in the field $(\bar{\chi}=5,67 \pm 1,456)$ are considered to be the most reliable communication channels (Table 2). This finding is in line with previous studies (Handa et al., 2013; Flicker, 2012).

\section{Channel reliability}

\begin{tabular}{|l|c|c|}
\hline \multicolumn{1}{|c|}{ Channel } & Mean & SD \\
\hline $\begin{array}{l}\text { Conferences organised by local } \\
\text { scientific societies }\end{array}$ & 5,78 & 1,290 \\
\hline Leading experts in the field & 5,67 & 1,456 \\
\hline $\begin{array}{l}\text { Conferences organised by } \\
\text { international scientific societies }\end{array}$ & 5,67 & 1,311 \\
\hline $\begin{array}{l}\text { Medical information received by e- } \\
\text { mail }\end{array}$ & 2,89 & 1,713 \\
\hline $\begin{array}{l}\text { Phone calls from pharmaceutical } \\
\text { representatives }\end{array}$ & 2,57 & 1,680 \\
\hline $\begin{array}{l}\text { SMS from pharmaceutical } \\
\text { representatives }\end{array}$ & 2,13 & 1,568 \\
\hline
\end{tabular}

On one hand, communication channels such as opinion leaders - the leading experts in the healthcare industry have the strongest contribution to increasing GPs' drugprescribing intentions $(\bar{\chi}=5,06 \pm 1,707)$, followed by articles published in local health journals $(\bar{\chi}=4,92 \pm 1,707)$ and conferences organised by local scientific societies $(\bar{\chi}=4,83 \pm 1,704)$. The significance of pharmaceutical representatives' contribution on increased intentions is placed $6^{\text {th }}$. Some of our results are in line with findings reported in earlier research as opinion leaders are very influential when introducing a new drug to the market (Groves et al, 2002). According to (Flicker, 2012), GPs tend to listen to opinion leaders rather than seek information elsewhere.

On the other hand, communication channels, such as medical information received by e-mail ( $\bar{\chi}=2,48 \pm 1,575)$, phone calls from pharmaceutical representatives $(\bar{\chi}=2,09 \pm 1,488)$ or SMS $(\bar{\chi}=1,70 \pm 1,279)$ have limited contribution to increase GPs' drug-prescribing intentions. These findings could not be compared to previous research, as we could not identify any available articles reporting similar/different findings (Table 3 ).
Channel importance in increasing drug prescribing intentions among GPs

\begin{tabular}{|l|c|c|}
\hline \multicolumn{1}{|c|}{ Channel } & Mean & SD \\
\hline $\begin{array}{l}\text { Opinion leaders - the leading } \\
\text { experts in the healthcare industry }\end{array}$ & 5,06 & 1,707 \\
\hline $\begin{array}{l}\text { Articles published in local health } \\
\text { journals }\end{array}$ & 4,92 & 1,707 \\
\hline $\begin{array}{l}\text { Conferences organised by local } \\
\text { scientific societies }\end{array}$ & 4,83 & 1,704 \\
\hline $\begin{array}{l}\text { Medical information received by e- } \\
\text { mail }\end{array}$ & 2,48 & 1,575 \\
\hline $\begin{array}{l}\text { Phone calls from pharmaceutical } \\
\text { representatives }\end{array}$ & 2,09 & 1,488 \\
\hline $\begin{array}{l}\text { SMS from pharmaceutical } \\
\text { representatives }\end{array}$ & 1,70 & 1,279 \\
\hline
\end{tabular}

Further, our study identified a statistically significant relationship between the channel frequency and the perceived reliability of that channel $(p=0,001)$. Also, empirical evidence suggests a statistically significant relationship between the channel reliability and the contribution of a particular communication channel to increasing GPs' drug-prescribing intentions $(\mathrm{p}=0,001)$.

\section{How Do GPs Perceive Both Traditional And Alternative Communication Channels?}

To address the second research question (RQ2: How do GPs perceive both traditional and alternative communication channels used to disseminate medical information?), perceived value of alternative (i.e., electronic and mobile-based) communication channels was evaluated and differences among GPs' perceptions by age groups were reported.

Our study suggests unexpected results regarding perceived value of alternative (i.e., electronic and mobilebased) communication channels among GPs. Locally designed websites for medical professionals have the highest perceived value $(\bar{\chi}=4,66 \pm 1,589)$, while the perceived value of information received by e-mail $(\bar{\chi}=3,14 \pm 1,907)$ or SMS $(\bar{\chi}=1,97 \pm 1,457)$ is rather low (Table 4). These findings could not be compared with earlier research as we were unable to identify any previous studies on any reported value perceptions by GPs about alternative (i.e., electronic and mobile-based) communication channels.

Table 4

GP's value perceptions of alternative (i.e., electronic and mobile-based) communication channels

\begin{tabular}{|l|c|c|}
\hline \multicolumn{1}{|c|}{ Channel } & Mean & SD \\
\hline $\begin{array}{l}\text { Locally designed websites for medical } \\
\text { professionals }\end{array}$ & 4,66 & 1,589 \\
\hline E-mail & 3,14 & 1,907 \\
\hline $\begin{array}{l}\text { Phone calls from pharmaceutical sales } \\
\text { representatives }\end{array}$ & 2,43 & 1,685 \\
\hline SMS & 1,97 & 1,457 \\
\hline
\end{tabular}

Statistically significant differences among GPs were found regarding both channel preference and perceived reliability of those communication channels by age group. 
Younger GPs (27-43 age group) are more likely to participate at international scientific conferences than the second (44-59 age group) ( $\mathrm{p}=0,002)$ or third group (6075 age group) of GPs $(p=0,003)$. Younger GPs $(27-43$ age group) are more likely to read articles published in international health journals $(\mathrm{p}=0,049)$ and use international websites dedicated to health practitioners more often $(\mathrm{p}=0,001)$ than their most senior colleagues (60-75 age group).

With regard to perceived reliability of communication channels, international conferences are considered more reliable by younger GPs (27-43 age group) compared to senior GPs (44-59 age group) $(\mathrm{p}=0.01)$. Younger GPs (2743 age group) also perceive international scientific publications as more reliable compared to most senior colleagues (60-75 age group) $(\mathrm{p}=0,02)$. The most senior group of GPs (60-75 age group) trust information acquired through visits and presentations by pharmaceutical sales representatives $(\mathrm{p}<0,001)$ and at local conferences organized by pharmaceutical companies $(\mathrm{p}=0,01)$.

\section{Conclusion and Practical Implications}

The aim of this study was to revisit traditional and alternative (i.e., electronic and mobile-based) communication channels most commonly used in the pharmaceutical industry to disseminate medical information and investigate GPs' perceptions of those channels in the drug prescription market of Lithuania.

The results suggest that pharmaceutical sales representatives and conferences organized by pharmaceutical companies are the most common channels used to disseminate the newest information to GPs.

While those channels play an important role in reaching GPs, our findings also reveal that leading experts in the field contribute significantly to increasing GPs' intentions to prescribe specific drugs to their patients, followed by local conferences and publications in Lithuanian language. International, local scientific conferences and leading experts in the field are also considered to be the most reliable ones among GPs.

With regard to perceived value of alternative (i.e., electronic and mobile-based) communication channels by GPs, only local websites designed for healthcare professionals received the highest evaluations from GPs.

In order to gain maximum benefits and efficiently disseminate information about prescription drugs, these channels can be combined effectively with each other, for example, by investing in satellite communications to allow opinion leaders to present their ideas at both local and international scientific conferences. Another group of communication channels that can be combined successfully are conferences sponsored by pharmaceutical companies or co-organised with scientific bodies to publish proceedings with conference papers presented that could be made freely available online. Given that websites designed for healthcare professionals have the highest perceived value among GPs, pharmaceutical companies might consider allocating more resources towards the development and maintenance of this popular online communication channel in Lithuania. Based on the findings, considerable reduction in the preparation and dissemination of e-mail or SMS advertising is recommended, as the perceived value of these channels is relatively small.

Interestingly, GPs' perceptions differ according to their age. For instance, younger GPs consider international conferences, international publications and international websites to be more reliable medical information sources compared to more senior GPs. Although pharmaceutical sales-representatives' visits to GPs do not appear to be the most important communication channel overall, they remain preferred by most senior GPs. Therefore, pharmaceutical companies should take into consideration the age of GPs when evaluating the effectiveness of traditional and alternative (i.e., electronic ad mobile-based) communication channels to reach their target audiences with medical information.

\section{Limitations and Future Research Directions}

As with any other research, this study has limitations that indicate future research directions.

First, our study did not use a probability sample. Probability sampling would involve a larger sample of GPs and allow generalisation of results on perceptions of both traditional and alternative (i.e., electronic and mobilebased) communication channels among GPs in Lithuania.

Second, our findings suggest statistically significant differences among GP groups by age regarding choice and reliability of communication channels. However, we did not aim to identify any reasons as to why those differences between younger and more senior GPs occur. Thus, further studies could aim to investigate the role of specific reasons (e.g., a language barrier, limited time to access information online or to visit a conference event) in channel preferences among GPs.

Next, our study did not examine features of alternative (i.e., electronic and mobile-based) communication channels available to GPs, but future studies could deepen our understanding of the role of interactive websites (e.g., social presence on a website) when accessing medical information online to increase GPs' involvement with the websites.

Further, our indicative data analysis suggests statistically significant relationships between channel usage frequency, perceived reliability and its importance in increasing drug-prescribing intentions among GPs. Gaining more knowledge on the relationship of reliabilitydrug-prescribing intentions would allow pharmaceutical companies to better understand causality of those concepts along with potential ethical issues that the usage of some communication channels may raise about GPs' priorities for specific prescription drugs (Makowska, 2014; Poulsen et al., 2013, Sah \& Fugh-Berman, 2013, Spurlig et al., 2010). 


\section{References}

Aaker, D. Kumar, V., Leone, R., \& Day, G. (2012). Marketing research, New York, Willey.

Anderson, R. (2014). Pharmaceutical Industry Gets High on Fat Profit. BBC News. Available from internet: http://www.bbc.co.uk/news/business-28212223

Burashnikova, I. S., Ziganshin, A. U., \& Ziganshina, L. E. (2008). Attitudes to Pharmaceutical Promotion Techniques among Healthcare Professionals in the Republic of Tatarstan, Russia. International Journal of Risk \& Safety in Medicine, 20, 57-71.

Businessvibes. (2012). Pharmaceuticals Industry - fact sheet. http://www.businessvibes.com/content/pharmaceuticalsindustry-fact-sheet

Castagnoli, W. (2008). A Split on DTC is Coming. Medical Marketing and Media, May2008, 43(5), 82p.

Castronovo, C., \& Huang, L. (2012). Social Media in an Alternative Marketing Communication Model. Journal of Marketing Development and Competitiveness, 6(1), 117-131.

Cavusgil, E., \& Calantone, R. (2011). Are Pharmaceutical Marketing Decisions Calibrated to Communications Effects? Health Marketing Quarterly, 28, 317-336. http://dx.doi.org/10.1080/07359683.2011.623105

Chimonas, S., Brennan, T. A., \& Rothman, D. J. (2007). Physicians and Drug Representatives: Exploring the Dynamics of the Relationship. Journal of General Internal Medicine, 22, 184-190. http://dx.doi.org/10.1007/s11606-006-0041-z

Churchill, Jr. G. A., \& Iacobucci, D. (2005). Marketing research: Methodological foundations (9th ed). Mason, Ohio: Thomson South-Western.

David, C. (2001). Marketing to the Consumer: Perspectives from Pharmaceutical Industry. Marketing Health Services, 21(1), 5-11.

De Laat, E., Windmeijer, F., \& Douven, R. (2002). How Does Pharmaceutical Marketing Influence Doctors’ Prescribing Behaviour? CPB Netherlands' Bureau for Economic Policy Analysis, The Hague, the Netherlands.

Fischer, M. A., Keough, M. E., Baril, J. L., Saccoccio, L., Mazor, K. M., Ladd, E., Von Worley, A., \& Gurwitz, J. H. (2009). Prescribers and Pharmaceutical Representatives: Why Are We Still Meeting? Journal of General Internal Medicine, 24(7), 795-801. http://dx.doi.org/10.1007/s11606-009-0989-6

Fisher, M., \& Albers, S. (2010). Patient- or Physician-Oriented Marketing: What Drives Primary Demand for Prescription Drugs?. Journal of Marketing Research, 47(1), 103-121.

Flicker, L. (2012). The Influence of Opinion Leaders. Australian Prescriber, 35(3), 74-5.

Folland, S., Goodman, A. C., \& Stano, M. (2004). The economics of health and health care (4th ed.). Upper Saddle River, N.J: Prentice Hall.

Gonul, F., Carter, F., Petrova, E., \& Srinivasan, K. (2001). Promotion of Prescription Drugs and its Impact on Physicians' Choice Behaviour. Journal of Marketing, 65(3), 79-90. http://dx.doi.org/10.1509/jmkg.65.3.79.18329

Groves, K. E. M., Flanagan, P. S., \& MacKinnon, N. J. (2002). Why Physicians Start or Stop Prescribing a Drug: Literature Review and Formulary Implications. Formulary, 37(4), 186-194.

Handa, M., Vohra, A., \& Srivastava, V. (2013). Perception of Physicians towards Pharmaceutical Promotion in India. Journal of Medical Marketing, 13(2), 82-92. http://dx.doi.org/10.1177/1745790413480519

Harms F., Rohmann S., Heinrich M., Druener M., \& Trommsdorff V. (2002). Innovative Marketing. Pharmaceuticals Policy and Law, 5, 135-149.

Jaakkola, E. \& Renko, M. (2007). Critical Innovation Characteristics Influencing the Acceptability of a New Pharmaceutical Product Format. Journal of Marketing Management, 23(3-4), 327-346. http://dx.doi.org/10.1362/ 026725707X196404

Janakiraman, R., Dutta, S., Sismeiro C., \& Stern P. (2008). Physicians’ Persistence and Its Implications for Their Response to Promotion of Prescription Drugs, 54 (6), 1080-1093.

Jones, M., Greenfield, S., \& Bradley, C. (2001). Prescribing New Drugs: Qualitative Study of Influences on Consultants and General Practitioners, British Medical Journal, 323(7309), 1-7. http://dx.doi.org/10.1136/bmj.323.7309.378

Ketis, Z., \& Kersnik, J. (2013). The Assessment of Pharmaceutical Sales Representatives by Family Physicians-Does it Affect the Prescribing Index? Family Practice, 30(3), 320-324. http://dx.doi.org/10.1093/fampra/cms078

Kim, H. (2011). Pharmaceutical Companies as a Source of Health Information: A Pilot Study of the Effects of Source, Web Site Interactivity, and Involvement, Health Marketing Quarterly, 28(1), 57-85. http://dx.doi.org/10.1080/ 07359683.2011 .545327

Kim, W. J., \& King, W. K. (2009). Product Category Effects on External Search for Prescription and Nonprescription Drugs, Journal of Advertising, 38(1), 5-19. http://dx.doi.org/10.2753/JOA0091-3367380101 
Kumar, A., \& Shafali. (2010). E-strategy for Pharmacy Marketing in Information Age. The Pharma Research, 4(1), 149153.

Ladeira, W. J., Dalmoro, M., Maehler, A. E., \& Araujo, C. F. (2011). Drug Prescription Practices in Brazil: a Structural Equation Model. International Journal of Pharmaceutical and Healthcare Marketing, 5(4), 262- 278. http://dx.doi.org/10.1108/17506121111190103

Lenskold, J. (2005). Finding The „Right Stuff“ to Revitalize Sales Productivity. Pharma Marketing News Supplement. https://www.fatfreecartpro.com/ecom/rp.php?rdffc=true\&txn_id=22S65225BH113251G\&client_id=16826\&d_id=24 $609061 \&$ emailed_link $=$ true \&nont $x n=\&$ gajs $=\&$ auser $=\&$ abeacon $=\&$

Levy, R. (1994). The Role and Value of Pharmaceutical Marketing, Archives of Family Medicine, 3(4), 327-332. http://dx.doi.org/10.1001/archfami.3.4.327

Lithuanian Department of Statistics (2012). Available from internet http://www.stat.gov.lt

Lithuanian PharmaZoom Data (2012). Available from internet http://www.pharmazoom.lt

Mack, J. (2005). Intelligent Online Sampling Strategies. Pharma Marketing News Supplement. Accessed on 01 October 2014:

Makowska, M. (2014). Interactions between Doctors and Pharmaceutical Sales Representatives in a Former Communist Country. Cambridge Quarterly of Healthcare Ethics, 23(3), 349-355. http://dx.doi.org/10.1017/S0963180113000960

McGettigan, P., Golden, J., Fryer, J., Chan, R., \& Feely, J. (2001). Prescribers Prefer People: The Sources of Information used by Doctors for Prescribing Suggest that the Medium is More Important than the Message. British Journal of Clinical Pharmacology, 51, 184-189. http://dx.doi.org/10.1111/j.1365-2125.2001.01332.x

Nair, H., S., Manchanda, P., \& Bhatia T. (2010). Asymmetric Social Interactions in Physician Prescription Behavior: The Role of Opinion Leaders. Journal of Marketing Research, 47 (5), 883-895. http://dx.doi.org/10.1509/jmkr.47.5.883

Pantelic, D. (2009). Internet as a Medium of Pharmaceutical Companies Promotional Activities. Management Information Systems, 4(1), 29-37.

Pedan, A., \& Wu, H. (2011). Asymmetric Responsiveness of Physician Prescription Behavior to Drug Promotion of Competitive Brands Within an Established Therapeutic Drug Class. Health Marketing Quarterly, 28, 133-154. http://dx.doi.org/10.1080/07359683.2011.545341

Pitt, L., \& Nel, D. (1998). Pharmaceutical Promotion Tools - Their Relative Importance. European Journal of Marketing, 22(5), 7-14. http://dx.doi.org/10.1108/EUM0000000005281

Poulsen, K., Glintborg, D., Moreno, S., Thirstrup, S., Aagard, L. \& Andersen, S. (2013). Danish Physicians' Preferences for Prescribing Escitalopram over Citalopram and Sertraline to Treatment-Naïve Patients: a National, Register-Based Study. European Journal of Clinical Pharmacology, 69(13), 1167-1171. http://dx.doi.org/10.1007/s00228-012-1447-7

PriceWaterhouseCoopers (2007). Pharma 2020: The vision. Which path will you take? http://www.pwc.com/en_ GX/gx/pharma-life-sciences/pdf/pharma2020final.pdf

PriceWaterhouseCoopers (2009). Pharma 2020: Marketing the future. Which path will you take? http://www.pwc.com/en_ GX/gx/pharma-life-sciences/pdf/ph2020-marketing.pdf

Prosser, H., Almond, S., \& Walley, T. (2003). Influences on GP's Decision to Prescribe New Drugs - the Importance of Who Says What, Family Practice, 20(1), 61-68. http://dx.doi.org/10.1093/fampra/20.1.61

Purcell, G. P., Wilson, P., \& Delamothe, T. (2002). The Quality of Health Information on the Internet, British Medical Journal, 324, 557-558. http://dx.doi.org/10.1136/bmj.324.7337.557

Qanadilo, H., \& Choi, K. (2012). The Personal Touch in Digital Promotion, Pharmaceutical Executive, 32(5), 96-97.

Reast, J. D., Lindgreen, A., Palihawadana, D., Spickett-Jones, G., \& Barnes B. R. (2011). Prescription Drug Communication Strategies: A Comparative Analysis of Physician Attitudes in Europe, the Middle East, and the Far East, Journal of Marketing Management, 27(3/4), 336-360. http://dx.doi.org/10.1080/0267257X.2011.547079

Rod, M. \& Saunders, S. (2009). The Informative and Persuasive Components of Pharmaceutical Promotion, International Journal of Advertising, 28(2), 313-349. http://dx.doi.org/10.2501/S0265048709200558

Sah, S., \& Fugh-Berman, A. (2013). Physicians under the Influence: Social Psychology and Industry Marketing Strategies. the Journal of Law, Medicine and Ethics, 41, 665-672. http://dx.doi.org/10.1111/jlme.12076

Schulz, S., Broekemier, G., \& Burkink, T. (2014). Attitudes and Beliefs Regarding Direct-to-Consumer Advertising of Pharmaceutical Drugs: An Exploratory Comparison of Physicians and Pharmaceutical Sales Representatives. Health Marketing Quarterly, 31(3), 279-291. http://dx.doi.org/10.1080/07359683.2014.936297

Scott, P., McIntosh-Scott, A., \& Stokes, P. (2013). Sales and Strategic Marketing Practices in the Pharmaceutical Industry: Doctors as Customers and their Decisions. Journal of International Business and Entrepreneurship Development, 7(1), 37-51. http://dx.doi.org/10.1504/JIBED.2013.052130 
Vilte Auruskeviciene, Jovita Butkeviciene, Laura Salciuviene. Revisiting the Role of Traditional, Electronic and Mobile

Spurling, G. K., Mansfield, P. R., Montgomery, B. D., Lexchin, J., Doust, J., Othman, N., \& Vitry, A. I. (2010). Information from Pharmaceutical Companies and the Quality, Quantity, and Cost of Physicians' Prescribing: a Systematic Review. PLoS Medicine, 7(10), 1-22. http://dx.doi.org/10.1371/journal.pmed.1000352

Stros, M., Hari, J., \& Marriott, J. (2009). The Relevance of Marketing Activities in the Swiss Prescription Drugs Market. International Journal of Pharmaceutical and Healthcare Marketing, 3(4), 323-346. http://dx.doi.org/10.1108/17506 120911006038

UK Department of Health. Medicines and Older People: Implementing medicines-related aspects of the NSF for Older People. (2001). http://www.dh.gov.uk/assetRoot/04/06/72/47/04067247.pdf

Vancelik, S., Beyhun, N., Acemoglu, H., \& Calikoglu, O. (2007). Impact of Pharmaceutical Promotion on Prescribing Decisions of General Practitioners in Eastern Turkey. BMC Public Health, 7, 122-129. http://dx.doi.org/10.1108/ 17506120911006038

World Health Organization. (2012). International Nonproprietary Names. http://www.who.int/medicines/services/inn/en/

World Health Organization (2015). http://www.who.int/trade/glossary/story073/en/

The article has been reviewed.

Received in June, 2015; accepted in November, 2015. 